\title{
Etnografia:
}

\section{uso, potencialidades e limites na pesquisa em saúde}

Andrea Caprara ${ }^{1}$

Lucyla Paes Landim²

CAPRARA, A.; LANDIM, L.P. Ethnography: its uses, potentials and limits within health research. Interface - Comunic., Saúde, Educ., v.12, n.25, p.363-76, abr./jun. 2008.

Ethnography is utilized more and more frequently to study different subjects within the domain of health: the functioning and evaluation of health systems; epidemiological research; scientific research conducted in laboratories; research on biotechnology; genetic research, among others. Some methodological questions arise from critical reading of these studies: How has ethnographic research evolved in the last decades? Which elements characterize ethnographic research applied to health? This paper is an attempt to reflect upon these issues by: 1 analyzing the development of the ethnographic method and its use in research on health; 2 discussing the methodological aspects of an ethnography carried out with elderly people in the city of Fortaleza, focusing particularly on participant observation.

Key words: Ethnography. Qualitative research. Observation. Public health. método etnográfico vem sendo crescentemente utilizado para estudar uma variedade de temas na área da saúde como: o funcionamento e avaliação do sistema sanitário; a investigação epidemiológica; a pesquisa científica de laboratório; a pesquisa biotecnológica; a pesquisa genética, entre outros. Isto nos leva a formular algumas perguntas metodológicas com base na leitura desses trabalhos: como foi se transformando a pesquisa etnográfica nos últimos decênios? Quais elementos caracterizam a pesquisa etnográfica aplicada em saúde? É buscando refletir sobre estas questões que desenvolvemos o artigo mediante dois sucessivos desdobramentos: 10 desenvolvimento do método etnográfico de pesquisa e sua utilização na pesquisa em saúde; 2 os aspectos metodológicos de uma pesquisa etnográfica realizada com pessoas idosas na cidade de Fortaleza, focalizando o interesse sobre a observação participante.

Palavras-chave: Etnografia. Pesquisa qualitativa. Observação. Saúde pública.

\footnotetext{
${ }^{1}$ Médico e antropólogo. Departamento de Saúde Pública, Universidade Estadual do Ceará (UECE). Av. Paranjana, 1.700 Itaperi - Fortaleza, CE 60.740-000 andreacaprara1@gmail.com ${ }^{2}$ Terapeuta Ocupacional. Doutoranda em Saúde Coletiva, Grupo de Pesquisa Humanidades, Saberes e Práticas em Saúde (UECE/CNPq).
} 


\section{Introdução}

A pesquisa em saúde foi acompanhada, neste último decênio, por um crescente interesse quanto à utilização de métodos qualitativos e seus instrumentos de pesquisa aplicados durante todo o séc. $X X$ pelas ciências sociais e na antropologia, em particular, no estudo de outros grupos culturais. Este interesse é atribuído a diversas razões, como, por exemplo, a importância dada atualmente pelas políticas sanitárias nacionais à dimensão qualitativa da prestação dos serviços assistenciais oferecidos aos cidadãos, colocando, de modo crescente, a necessidade de se introduzirem instrumentos de pesquisa e avaliação voltados à valorização do ponto de vista dos usuários (Gomes et al., 1999). Assim, se em grande parte estranhos à tradição da pesquisa em saúde, os métodos de pesquisa qualitativa assumem particular relevância neste quadro de referência.

Dentro desta moldura teórico-metodológica, o método etnográfico vem sendo utilizado por diversos autores para estudar uma variedade de temas na área da saúde, desde o funcionamento do sistema sanitário: a avaliação da qualidade dos serviços de saúde do ponto de vista dos usuários (Andrade, Vaitsman, 2002; Atkinson, 1993); a relação médico-paciente e o ensino médico (Nations, Gomes, 2007; Bonet, 2004; Menezes, 2001; Nunes, 1993); a avaliação do Programa de Saúde da Família (Trad et al., 2001); as interpretações e práticas da população (Iriart, Andrade, 2002; Nations, Nuto 2002; Rego, Barreto, Killinger, 2002; Killinger et al., 2000; Alves, 1998; Rodrigues, Caroso, 1998; Souza, 1998); a investigação epidemiológica (Almeida Filho et al., s/d); até temas como a pesquisa científica de laboratório (Latour, Woolgar, 1997), a pesquisa biotecnológica (Rabinow, 1999, 1996), a pesquisa genética (Bibeau, 2004); a discussão sobre práticas de transplantes no Japão (Lock, 1995), e outros que compõem hoje o abrangente campo da Saúde Coletiva (Paim, Almeida Filho, 1998).

Algumas perguntas metodológicas surgem com base em uma análise desses trabalhos: como foi se transformando a pesquisa etnográfica nos últimos decênios? Quais elementos caracterizam a pesquisa etnográfica aplicada em saúde? Pode definir-se como etnográfica uma pesquisa baseada exclusivamente em grupos focais ou entrevistas abertas, sem ter havido, no processo de pesquisa, uma observação cuidadosa das práticas realizadas (Brink, Edgecombe, 2003)? É esta última questão que nos suscita, por exemplo, o artigo de Trad. et al. (2001), que apresenta um estudo etnográfico em que se utilizaram fundamentalmente grupos focais na coleta dos dados. Torna-se pertinente perguntar se o recente e crescente uso da etnografia na pesquisa em saúde não se caracterizaria quase como uma distorção de suas premissas originais, configurando-se no que se poderia chamar de observação de "tipo" etnográfico.

Este artigo busca responder a estas questões procurando refletir por meio de dois sucessivos desdobramentos: 1) na primeira parte, depois de uma breve análise dos principais debates que marcaram o desenvolvimento da etnografia na antropologia, analisamos como a abordagem etnográfica vem sendo utilizada hoje por diversos autores nas pesquisas em saúde; 2) na segunda parte, apresentamos os aspectos metodológicos de um estudo etnográfico realizado com pessoas idosas na cidade de Fortaleza, focalizando a observação participante e o registro no diário de campo. Trata-se de um estudo realizado em um bairro da cidade, que investigou como pessoas idosas freqüentadoras de grupos para idosos percebem a própria saúde e como cuidam de si nas experiências cotidianas.

\section{O método etnográfico de pesquisa: refletindo sobre o seu desenvolvimento}

Para abordar o desenvolvimento do método etnográfico na área da saúde é necessária uma primeira reflexão sobre o uso de métodos qualitativos na Saúde Coletiva. Como referido na introdução, neste último decênio assistimos a um consistente crescimento das publicações na área da saúde sobre pesquisas realizadas com métodos qualitativos (Meyer, 2000; Pope, Mays, 2000; Jones, Hunter, 1995). Entre os temas abordados, lembramos: os estudos sobre a experiência de pacientes com doenças crônicas, as pesquisas sobre a organização dos serviços de saúde e a humanização da assistência, o trabalho em equipes multidisciplinares. A literatura brasileira também apresenta uma vasta produção bibliográfica sobre a utilização de métodos qualitativos em Saúde Coletiva (Almeida Filho, 2003; Minayo, Minayo-Goméz, 2003). 
Quando falamos de métodos qualitativos, em realidade, trata-se de uma ampla bagagem de métodos de pesquisa voltados à coleta de dados sobre o "universo social" (Pope, Mays, 2000). Por essa razão, eles demandam, por parte do pesquisador, um percurso de exploração e interpretação de dados provenientes de diversas fontes. As pesquisas qualitativas e as quantitativas têm diferentes finalidades e por isso necessitam de diferentes desenhos de pesquisa. A lógica da pesquisa qualitativa, muitas vezes, é mais do tipo indutivo que dedutivo, e consiste na descrição de pessoas e grupos em situações particulares. A pesquisa qualitativa procura entender os significados, as experiências e, muitas vezes, é flexível, dinâmica (os métodos e os aspectos relacionados ao desenho do estudo podem, em parte, modificar-se na medida em que novas informações são recolhidas). Também a análise e interpretação dos dados mudam com o tempo na medida em que o pesquisador acrescenta novos elementos e conhece melhor o contexto estudado, fato comum em estudos etnográficos (Rosaldo, 1993). Podemos afirmar que é um processo não linear, não seqüencial. Além disso, boas pesquisas qualitativas também procuram responder a perguntas bem formuladas.

Em síntese, alguns autores concordam em identificar três estratégias de coleta de dados que caracterizam os métodos qualitativos: 1 entrevista face a face que, por sua vez, pode ser semi-estruturada, aberta, aprofundada, e/ou história de vida; 2 entrevista em grupo e/ou grupos focais; 3 observação direta da vida humana, participando de eventos sociais e culturais com as pessoas em seus locais de vida (observação direta e/ou observação participante); e ainda vale acrescentar, como um quarto elemento, a coleta de dados em documentos escritos (Patton, 1987). Os dados coletados são sucessivamente organizados segundo grandes temas, categorias, casos semelhantes, e sua análise consiste no constante confronto de elementos que emergem das diversas entrevistas e observações, procurando elementos comuns e possíveis diferenças. Uma particular atenção refere-se à semântica da frase utilizada, a transcrição, no texto final, de frases provenientes das pessoas entrevistadas, a organização temática. A análise dos dados não se limita à análise de categorias predefinidas, permitindo uma análise em profundidade de elementos que vão surgindo durante a coleta dos dados. O fenômeno não pode ser compreendido fora do seu contexto, por isso o significado emerge da relação com outros signos e, na antropologia, o significado é sempre construído culturalmente: nada é o que parece ser (Banyai, 2002).

Essas características da pesquisa qualitativa estão no centro dos debates entre comunidade científica e sociedade, influenciando o desenvolvimento e a aplicação de métodos qualitativos de pesquisa, entre os quais a abordagem etnográfica, em setores e instituições as mais diversas, como economia e comunicação. No campo da Saúde Coletiva, o desenvolvimento de políticas e formas de organização sociossanitária (sistemas de informação, análise da demanda, avaliação de serviços) tem enriquecido o debate num campo marcado pela epidemiologia tradicionalmente vinculada aos métodos quantitativos de pesquisa.

Uma segunda razão refere-se às mudanças ocorridas, sobretudo, nestes últimos decênios na antropologia, por meio da atenção particular dos pesquisadores dirigida às próprias sociedades ocidentais. A mudança de atenção da tradicional tarefa de estudar as sociedades "primitivas" para a análise cultural da sociedade de pertença produziu uma série de questões metodológicas centrais, assim como uma reflexão sobre o objeto, o contexto e os próprios instrumentos da pesquisa antropológica (Latour, Wolgar, 1997; Rabinow, 1996). Trata-se de uma mudança reflexiva que tem salientado a relatividade de definições, como aquelas de indivíduo, sociedade, identidade, trazendo ao centro o discurso sobre a natureza relacional e lingüística dos recursos culturais construídos e utilizados pelas pessoas (Benini, Naclerio, 2004).

Uma terceira razão é ligada ao próprio percurso histórico que marca o desenvolvimento das ciências humanas em contraposição às ciências da natureza. Nos primeiros decênios do século XX, a antropologia se caracterizava por um certo "biologicismo", conjuntamente com o desenvolvimento do positivismo das ciências biomédicas. Em etapas sucessivas, os antropólogos começaram a contrapor às ideologias científicas dominantes sobre saúde, doença, corpo, o caráter culturalmente construído desses conceitos, procurando entender as formas por intermédio das quais os indivíduos expressam e interpretam o sofrimento, a dor. Nos últimos decênios, surgiu um interesse crescente na pesquisa em Saúde Coletiva para se entender a construção cultural da saúde e da doença elaborada pelos diferentes 
grupos culturais e estudada por meio da pesquisa etnográfica. Nasce, assim, um interesse, por parte de pesquisadores na área da saúde, pela experiência individual, familiar e cultural da doença, que pode ser estudada, sobretudo, por meio de métodos qualitativos (Nations, Nuto, 2002; Wiklund, Lindholm, Lindström, 2002; Caprara, 1998; Rodrigues, Caroso, 1998; Souza, 1998).

O método de investigação por excelência da antropologia é a etnografia, considerada, por Hammersley e Atkinson (1994), como a forma mais básica de investigação social e que trabalha com uma ampla gama de fontes de informações. Por método etnográfico entende-se uma atividade de pesquisa no terreno, por prolongados períodos de tempo, com contato direto com o objeto de estudo, seguido pela sistematização em formato de texto da experiência (Fabietti, Remotti, 1997). Mas além da longa estada no terreno, a pesquisa etnográfica não é o espaço empírico no qual aplicar ou avaliar uma teoria antropológica. Trata-se de uma atividade durante a qual vai sendo construído o saber teórico conjuntamente à coleta dos dados (Pizza, 2005). Assim, não é somente um método de pesquisa, mas um processo conduzido com uma sensibilidade reflexiva, tomando em conta a própria experiência no campo junto às pessoas com as quais o antropólogo trabalha (Geertz, 1989). Para Cardoso de Oliveira (2000, p.24), isto faz com que os "horizontes semânticos em confronto - o do pesquisador e o do nativo - abram-se um ao outro, de maneira a transformar tal confronto em um verdadeiro 'encontro etnográfico'" . Para esse autor, o trabalho do antropólogo consiste em olhar, ouvir e escrever. Este último aspecto não pode ser subtraído ou negligenciado pelo pesquisador, desde que

ao tentar penetrar em formas de vida que Ihe são estranhas, a vivência que delas passa a ter cumpre uma função estratégica no ato de elaboração do texto, uma vez que essa vivência só assegurada pela observação participante "estando lá" - passa a ser evocada durante toda a interpretação do material etnográfico no processo de sua inscrição no discurso da disciplina. (Cardoso Oliveira, 2000, p.34)

No começo, na fundação das ciências sociais, a etnografia era considerada como simples coleta de dados para representar a autenticidade de uma cultura. O pesquisador não explicitava como havia colhido esses dados, como havia desenvolvido o trabalho de campo, nem quais os pressupostos teóricos que o orientavam. De acordo com Clifford (2002), nem sempre etnografias foram escritas por antropólogos e, antes do final do séc. XIX, etnógrafos e antropólogos eram personagens distintos. É a partir de Boas e Malinowski que se dá a identificação da etnografia como método de investigação social característico da antropologia. Esses dois autores viveram na mesma época e ambos priorizaram o trabalho de campo e a observação participante enquanto método primordial de pesquisa etnográfica (Laplantine, 2001).

Malinowski vai inovar o modo de se fazer etnografia ao permanecer por um longo período em campo, convivendo com os nativos, o que lhe permitiu uma análise aprofundada das culturas que estudou (Durham, 2004). A observação participante ocupa um lugar central em seu método de investigação e ele sugere alguns princípios e métodos que o etnógrafo deve adotar para levar a cabo a tarefa: conviver intimamente com os nativos; reunir informações diversificadas sobre um mesmo fato; reunir um grande número de dados sobre fatos diferentes e sistematizá-los em quadros sinópticos a fim de torná-los compreensíveis para todos (Malinowski, 1986).

Grande importância é conferida à descrição detalhada do trabalho de campo e de como se dá o processo de inserção, observação e coleta de informações por parte do etnógrafo, lembrando que, na pesquisa etnográfica, a distância entre o material bruto da informação coletado e a apresentação final dos resultados é freqüentemente enorme (Malinowski, 1986). A este respeito Geertz (2000), fundador da Antropologia Interpretativa, corrente filiada à hermenêutica, vai se referir ao "estar lá" (no campo) e ao "estar aqui" (no gabinete). É a introdução deste relato detalhado das vicissitudes pelas quais passa o etnógrafo, junto com a descrição minuciosa e apaixonante do que chama de "imponderáveis da vida real" - aqueles fatos cotidianos sutis, mas ricos de significados, como os cuidados com o corpo, o modo de comer, o tom das conversas e da vida social, a amizade, simpatia ou aversão entre as pessoas e outros - que vai "criar, para o leitor, a imagem viva e humana de um povo completamente diferente de nós" (Durham, 1986, p.9). 
Este aspecto do relato vivido da escrita etnográfica é muito enfatizado por Malinowski (1986), e vai se colocar como fundamental para o posterior desenvolvimento da etnografia. Como ressalta Clifford (2002, p.21): "A etnografia está, do começo ao fim, imersa na escrita. Esta escrita inclui, no mínimo, uma tradução da experiência na forma de texto". Para Geertz (1989), o texto terá grande importância pois é na forma de texto que ocorre a interpretação, que pode ser múltipla, pois é inerente ao texto ser passível de diferentes interpretações, quão diferentes sejam seus leitores e pontos de vista, visões e concepções de mundo.

Esta segunda forma metodológica, à qual se filia Geertz, adquire maior relevância a partir da década de 1960, em que se dá mais importância a uma análise aprofundada de fenômenos particulares em vez de se tentar identificar generalidades (Geertz, 1993). Naquela época, temos o nascimento de uma série de teorias interpretativas interessadas em estudar a estrutura social/relações humanas; regras sociais/ formas de comunicação; coisas em comum/diferenças, e outros temas. Estas idéias de Geertz permitem diferenciar entre estudos sistêmicos, que analisam a cultura como um sistema de relações, e estudos de análise processual, que conferem importância a histórias de vida, ou seja, estudos de casos concretos por meio do que Geertz denomina "descrição densa" (thick description).

Hoje, além dos estudos sobre políticas globais e cultura (Appadurai, 1996) e as críticas epistemológicas da teoria estrutural, em defesa de uma racionalidade prática (Da Silva, 2002; Obeyesekere, 1997), temos de considerar que a pesquisa etnográfica é entendida sempre mais como diálogo entre as construções interpretativas do pesquisador e das pessoas estudadas (Rabinow, 1996; Clifford, Marcus, 1986). Com o modelo dialógico, temos o abandono da "pura objetividade" do etnógrafo e o desenvolvimento de um modelo polifônico, baseado no diálogo entre o etnógrafo e a pessoa entrevistada, com negociação dos significados das experiências dos sujeitos no campo (Clifford e Marcus, 1986). Os resultados nunca são definitivos.

Este é o modelo proposto também por Rosaldo (1993), que critica o conceito weberiano de apaixonada distância, introduzindo o conceito de sujeito posicionado. Rosaldo sugere que o pesquisador teria de explorar os sujeitos de sua pesquisa a partir de uma posição, como ele chama, do sujeito que se reposiciona. O pesquisador começa com uma série de perguntas que se modificam no processo da pesquisa.

Como exemplo, a própria experiência etnográfica de Rosaldo com os llongot, caçadores de cabeças nas Filipinas, e a raiva que os membros desse grupo tinham depois da morte de alguém da família. Na posição de pesquisador, Rosaldo sentia dificuldade de compreender esta raiva e o papel dela como motor principal da caça. A experiência da morte de sua esposa em um acidente o levou ao tema e à análise da raiva no luto, de forma completamente diferente. A sua experiência pessoal serviu como veículo para que a raiva dos Ilongot fosse mais acessível à compreensão do leitor. Neste sentido, abre uma crítica aos estudos sociológicos e etnográficos anteriores.

Tomando o exemplo dos estudos sobre a morte (rituais da morte), Rosaldo (1993) afirma que autores que tocam este tema eliminando as emoções intensas não somente distorcem as descrições, mas eliminam também importantes variáveis de análise. Critica, então, os estudos da morte em que o pesquisador fica em uma posição de observador destacado; e enfatiza o pesquisador que se reposiciona continuamente, o "positioned subject".

O conceito de posição se refere a como a experiência da vida do pesquisador pode facilitar ou inibir o estudo de tipos particulares de problemas, assim como sua idade, sexo, etc. Estando a cultura vinculada com o poder, o pesquisador teria de se questionar, no início de seu trabalho, sobre a própria posição social que ocupa e aquela dos entrevistados. Por exemplo: a pessoa que entrevistamos fala a partir de uma posição de poder ou de subordinação? Que tipo de experiência ela tem? Quais são as formas complexas que constituem a sua identidade social?

Neste sentido é que Geertz (1989) afirma ter de existir uma contínua tensão entre análise científica e experiência da vida cotidiana. O termo que mais reflete esta tensão entre a participação e a observação destacada é observação participante, que expressa um paradoxo: o primeiro termo (observação) convida a uma distância. O segundo termo (participante) convida a um envolvimento emocional. Clifford (2002) tenta superar este paradoxo definindo a observação participante como dialética entre experiência e interpretação. Existe uma passagem contínua entre o "interno", a 
interpretação, a análise dos fatos e o "externo", o contexto mais amplo: "entendida de modo literal, a observação participante é uma fórmula paradoxal e enganosa, mas pode ser considerada seriamente se reformulada em termos hermenêuticos, como uma dialética entre experiência e interpretação" (Clifford, 2002, p.33). Daí ser necessário entender o significado de experiência enquanto processo de conhecimento, e não de simples vivência pessoal (Fabietti, 1999).

Este interesse em relação ao estudo de fenômenos específicos encontra, no plano metodológico, a sua expressão nos estudos da experiência subjetiva, da história individual, e as histórias de vida passam a ser métodos importantes nesse processo, incorporados nos estudos de Saúde Coletiva (Alencar, 2006; Van Manen, 2002, 1990). Conceitos importantes são experiência e subjetividade. A etnografia contemporânea, portanto, deixa espaço à subjetividade do etnógrafo, à utilização da primeira pessoa no texto etnográfico, à colocação de considerações auto-reflexivas. Produz auto-reflexão também entre os membros do grupo estudado.

$\mathrm{Na}$ antropologia, neste último decênio, produziu-se uma outra mudança por meio da atenção particular dos antropólogos dirigida às próprias sociedades ocidentais nas quais têm se desenvolvido. Rabinow (1996) e Latour e Woolgar (1997) inovam o objeto da etnografia ao voltarem-se para o modo como a ciência produz seus resultados. A mudança de atenção da tradicional tarefa de estudar as sociedades "primitivas" para a análise cultural da sociedade de pertença produziu uma série de questões metodológicas centrais, assim como uma reflexão sobre o objeto, o contexto e os próprios instrumentos da pesquisa antropológica.

A primeira questão foi colocada por Lévi-Strauss (1986), que intitulou um dos seus livros "O olhar distanciado". Um pesquisador que observa a própria sociedade tem maiores dificuldades em encontrar as especificidades culturais em relação a um observador externo. O segundo aspecto refere-se à maneira de observar as práticas científicas. Bibeau (2004), em livro recente, identifica dois grupos de pesquisadores: o primeiro se especializou nos estudos etnográficos de laboratório, analisando de perto os locais de produção do pensamento científico. Para Bibeau, esses estudos aparecem como reducionistas, sobretudo aqueles que se aproximam do estilo de Latour, que analisa especialmente os processos de construção do pensamento científico. Um segundo grupo de pesquisadores estuda os processos científicos dentro de uma visão mais ampla, analisando não somente a vida de laboratório, mas também a produção das invenções por meio dos copyright e o mercado com suas alianças, conflitos, dedicando uma atenção particular especialmente ao que se refere ao mercado bioindustrial acionário.

Na segunda parte deste artigo, discutimos os aspectos metodológicos referentes à observação participante com base nos registros em diário de campo e relatório de pesquisa de um estudo etnográfico realizado com pessoas idosas na cidade de Fortaleza.

\section{Observar, participar, interpretar: percursos de um estudo etnográfico}

Paes Landim (2004) realizou um estudo etnográfico, particularmente influenciado pela antropologia interpretativa de Geertz, com o objetivo de investigar como pessoas idosas em situação socioeconômica desfavorável e que freqüentam grupos de idosos percebem a própria saúde e como cuidam de si nas experiências cotidianas. O estudo teve a aprovação prévia do Comitê de Ética em Pesquisa da UECE.

Nesta perspectiva, uma grande importância é conferida à observação dos eventos, dos rituais, que permitem desvendar elementos ou aspectos referentes às regras, à cultura do grupo. O desenho do estudo, portanto, serviu-se do profícuo diálogo das Ciências Sociais com a Saúde, especificamente a antropologia que, como coloca Durham (2004), apresenta um material provocativo e estimulante para repensar a realidade social.

A pesquisa de campo foi desenvolvida em Fortaleza, no período de janeiro de 2003 a fevereiro de 2004, com um grupo de idosos do Centro Comunitário Luíza Távora, localizado no bairro Vicente Pinzón. Este bairro, contexto do estudo, possui uma população de 39.551 pessoas, 2.371 das quais têm sessenta anos ou mais. O número de pessoas alfabetizadas chega a um total de 28.757, sendo 1.423 com sessenta anos ou mais (Instituto Brasileiro de Geografia e Estatística, 2000). 
Esses dados, entretanto, não são suficientes para contextualizar o bairro. Um bairro, além de deter características históricas, estéticas, topográficas, socioprofissionais e outras, também é o lugar onde:

a relação espaç̧o/tempo é a mais favorável para um usuário que deseja deslocar-se por ele a pé, saindo de sua casa. Por conseguinte, é o pedaço de cidade atravessado por um limite distinguindo o espaço privado do espaço público: é o que resulta de uma caminhada, da sucessão de passos numa calçada, pouco a pouco significada pelo seu vínculo orgânico com a residência. (Certeau, Girad, Mayol, 2003, p.41)

Neste sentido, torna-se compreensível o que foi revelado pelo andar mais lento dos idosos que transitam ininterruptamente pelas ruas, becos e ruelas do bairro que ajudaram a construir ativamente.

Realizar um estudo etnográfico pressupõe algum tempo de convívio com o grupo que se quer conhecer. E toda investigação prevê uma ou mais idas ao campo antes do trabalho mais intensivo, numa avaliação da situação em que se trabalhará, buscando: "prever os detalhes do primeiro impacto da pesquisa, ou seja, como apresentá-la, como se apresentar, a quem se apresentar, através de quem, com quem estabelecer os primeiros contatos" (Minayo, 2000, p.103). Este momento é registrado no diário de campo do pesquisador:

Fui conhecer o grupo. Uma parte deles estava aguardando a coordenadora sentados em cadeiras de plástico, no alpendre em frente à sala onde ocorre a atividade do grupo, e outra parte no quintal sob a sombra de uma árvore frondosa. Cumprimentei as pessoas, procurei uma cadeira e sentei-me nas que estavam no alpendre, mais protegida do sol. Dei uma olhada no grupo. Era composto basicamente por mulheres, alguns poucos homens. Contei setenta pessoas. (Senti que, quando cheguei, todos olharam para mim, um pouco de curiosidade. Observei que fui bem acolhida na "primeira impressão" e isso foi recíproco). (Paes Landim, 2004)

Outro trecho retrata este momento inicial da entrada em campo do pesquisador e indica que as primeiras incursões ao grupo que se quer estudar se caracterizam pela adoção de estratégias de aceitação, tão comum e necessária para se fazer um trabalho de pesquisa utilizando o método etnográfico:
Às 9 h00 acompanho a coordenadora ao pátio e ao salão onde os idosos estão reunidos. O sol está forte, faz calor. Como da outra vez em que estive no grupo, estão todos sentados em cadeiras de plástico sob a sombra de duas amendoeiras altas e frondosas no meio do pátio; outros se sentam à sombra do alpendre. Percebo que as pessoas me reconhecem. Dou bom-dia a todos e sento-me junto deles. As pessoas com as quais conversei mais diretamente da última vez sinalizam boas-vindas com as mãos. Fico contente em revê-las. (Paes Landim, 2004)

O diário de campo é o instrumento mais básico para o pesquisador que está fazendo uma etnografia. É um documento pessoal e nele escrevemos observações, experiências, sentimentos, sensações, até "percepções de pele"; porém, a imagem do diário inspirada nos trabalhos dos primeiros antropólogos, de um caderno com capa dura, manuscrito, está sendo superada com o crescente uso de laptops/notebooks "com condições de comportar sofisticados programas de recepção e gerenciamento de dados qualitativos" (Víctora, Knauth, Hassen, 2001, p.73). Entretanto, mesmo utilizando um diário de campo eletrônico, o pesquisador deve manter a função deste instrumento, que é a de registrar, do modo mais fiel e detalhado possível, cada ida ao campo: "muitas vezes são as informações do diário de campo que nos dão subsídios para analisar os dados coletados de outra forma. Deve-se manter a lógica de um diário de viagem, no qual se escreve todo dia sem restrições" (Víctora, Knauth, Hassen, 2001, p.73).

A entrada em campo é um momento rico de significados sutis, que requer cuidado e empatia por parte do pesquisador. 
No primeiro dia, conversei com algumas pessoas que estavam sentadas ao meu lado. Ouvi histórias de amor, histórias de doença, vi as pessoas conversarem alto, sorrirem, silenciarem, rezarem, dançarem, comerem e, por fim, irem embora não sem antes (muitas dessas pessoas eu ainda não sabia o nome) me abraçarem, ou me beijarem, ou apertarem minha mão, dando-me as boas-vindas. Nada de estranhamento, e sim acolhimento. As pessoas aceitaram a minha presença no grupo com simplicidade e espontaneidade e, por ter sido apresentada como pesquisadora, com uma certa curiosidade. (Paes Landim, 2004)

A partir da aceitação do pesquisador pelo grupo, pode-se levar a cabo a observação participante, que implica, necessariamente, uma relação social entre o pesquisador e os pesquisados. A qualidade dos dados obtidos depende, em grande parte, da maneira como essa relação se estabelece. Para Cardoso de Oliveira (2000), uma verdadeira interação entre pesquisador e informante ocorre quando este último passa à condição de interlocutor. Dessa forma é possível manter uma relação dialógica, de proximidade e confiança, baseada em princípios éticos. E é importante que o relatório de pesquisa esclareça como isso se deu:

Passei a freqüentar as reuniões do grupo uma vez por semana e a participar das atividades desenvolvidas, como o momento da oração, os trabalhos corporais, o forró, e outras. Em pouco tempo, minha presença foi fazendo parte da paisagem do grupo. Tanto os idosos, quanto a coordenadora desenvolvemos uma relação recíproca de confiança e afeto. Mas, principalmente com os idosos, o contato corporal era intenso. Eu, literalmente, era abraçada por setenta pessoas tantas vezes eu freqüentasse o grupo. E retribuía os abraços com a mesma intensidade. Porém, esta reciprocidade afetiva não dissolveu a alteridade, presente independentemente da vontade do pesquisador, como diria Zaluar, nos gestos, na posse de objetos como o gravador, na minha agenda capa dura vermelha... Antes, esta reciprocidade foi positiva e baseada numa relação de confiança que foi se construindo no trabalho de campo. (Paes Landim, 2004)

Para Clifford (2002, p.20), o trabalho de campo etnográfico

permanece como um método notavelmente sensível. A observação participante obriga seus praticantes a experimentar, tanto em termos físicos quanto intelectuais, as vicissitudes da tradução. [...]; como meio de produzir conhecimento a partir de um intenso envolvimento intersubjetivo, a prática da etnografia mantém um certo status exemplar.

Como participava até o final das reuniões do grupo, que costumam encerrar por volta do meio-dia, terminei por estabelecer uma rotina de dar carona para algumas pessoas que moravam por onde eu passava. Também aceitei alguns convites para tomar café em algumas casas, convites sempre acrescidos de "minha casa é simples, mas você será muito bem-vinda" ou "é casa de pobre, não tem nada, mas o coração é grande" [confirmando Damatta (2000) sobre a nossa hospitalidade]. E assim fui estreitando os laços com as pessoas. Dessa forma, fiquei conhecendo melhor o bairro e já sabia localizar suas casas. (Paes Landim, 2004)

A permanência em campo exige que se reflita sobre o vínculo na relação entre pesquisador e pesquisado, que sempre envolve um alto grau de subjetividade. Este é outro momento delicado para o pesquisador que está fazendo uma etnografia, quando precisa aprofundar o estudo e, concomitante à observação participante, lançar mão da entrevista em profundidade e/ou história de vida. Como selecionar, num grupo, informantes-chave? Quem entrevistar e/ou de quem colher a história de vida? Isto requer algum tipo de critério e se coloca, muitas vezes, como um dilema para o pesquisador.

Paes Landim (2004) recorreu a Éclea Bosi (1994, p.37), que relata: 
O principal esteio do meu método de abordagem foi a formação de um vínculo de amizade e confiança com os recordadores. Esse vínculo não traduz apenas uma simpatia espontânea que se foi desenvolvendo durante a pesquisa, mas resulta de um amadurecimento de quem deseja compreender a própria vida revelada do sujeito.

Aprendi o nome de Liberalina desde o primeiro momento em que fomos apresentadas formalmente. Sua figura graciosa, pequenina, sempre com um chapéu de crochê azul que, soube mais tarde, ela mesma confeccionava, me chamou a atenção logo no primeiro dia de observação. A empatia foi recíproca, e ao longo das minhas incursões no campo, de conversas entre uma atividade ou outra do grupo, de caronas ao meio-dia, estabelecemos uma relação de confiança afetuosa. Liberalina, 86 anos, era freqüentadora assídua do grupo. Seu corpo magro tinha uma prontidão, aos meus olhos, impressionante, para o movimento. Participava ativamente das atividades corporais, dança, jogos, dramatizações, propostas pela coordenadora do grupo. (Paes Landim, 2004)

Neste momento surge uma série de perguntas sobre como compreender aquela realidade que se apresenta, e quais as ferramentas teóricas com as quais se pode contar. Mais do que nunca faz sentido a leitura de Geertz (1989, p.7):

O que o etnógrafo enfrenta, de fato - a não ser quando está seguindo as rotinas mais automatizadas de coletar dados - é uma multiplicidade de estruturas conceituais complexas, muitas delas sobrepostas ou amarradas umas às outras, que são simultaneamente, estranhas, irregulares e inexplícitas, e que ele tem de alguma forma, primeiro apreender e depois apresentar. [...]. Fazer a etnografia é como tentar ler no sentido de construir uma leitura - um manuscrito estranho, desbotado, cheio de elipses, incoerências, emendas suspeitas e comentários tendenciosos, escritos não como os sinais convencionais do som, mas com exemplos transitórios do comportamento modelado.

Nos momentos em campo, havia uma intensa troca de informações. As conversas informais que mantinha com as pessoas foram me revelando o universo em que viviam, o que pensavam, o que faziam no cotidiano, e muitas das perguntas que eu havia me feito foram respondidas durante a observação participante. (Paes Landim, 2004)

A observação participante realizada junto ao grupo revelou que os limites atribuídos aos idosos não são definidos por eles próprios, e sim por um outro, geralmente mais jovem, que tenta destituir de poder aqueles que estão vivenciando o envelhecimento. O estudo etnográfico mostra que os idosos estão em constante movimento, buscando superar limitações impostas pelas duras condições de existência em que vivem desde a infância, e que se perpetuaram ao longo de suas vidas: trabalho na infância, fome, privações, ausência de estudo, ausência de trabalho remunerado condignamente, ausência de assistência adequada à saúde, dependência do assistencialismo estatal. O cuidado de si, observado no dia-a-dia, revela uma série de táticas cotidianas de cuidados medicinais, dietéticos, corporais, de desenvolvimento de novas aprendizagens, como ofícios artesanais, o retorno ao estudo; e a intensa participação em grupos de idosos e grupos de orações, que contribuem para a manutenção da sociabilidade, autonomia, interesse pela vida, novos projetos, que influem diretamente no bem-estar e saúde desse grupo.

\section{Conclusão}

A proposta foi abrir um debate sobre a pesquisa etnográfica, mostrando sua evolução nos últimos decênios e como vem sendo utilizada hoje para estudar uma variedade de temas na área da Saúde. O recente e crescente uso da etnografia na pesquisa nessa área teria de proporcionar um melhor 
conhecimento dos aspectos estudados, porém, muitos desses estudos não se fundamentam na observação cuidadosa das práticas realizadas. É necessário perguntar-se se o recente e crescente uso da etnografia pela Saúde não se caracterizaria quase como uma distorção de suas premissas originais, configurando-se no que se poderia chamar de observação de "tipo" etnográfico. Entende-se que isto possa estar ocorrendo em consequência de algumas dificuldades enfrentadas hoje pelos pesquisadores, como o pouco tempo dado pelos programas de pós-graduação e pelas agências fomentadoras para se fazer pesquisa, como também pelas dificuldades inerentes ao método, que exige um treinamento prévio do pesquisador e uma familiaridade com os textos clássicos da antropologia, além de leituras de relatórios de pesquisa e diários de campo,e, certamente muito importante, capacidade de escrita. Questões éticas também se colocam hoje para o pesquisador que se propõe fazer uso da etnografia. Ao entrar em um grupo ou uma instituição para realizar investigação etnográfica, o pesquisador passa a olhar, ouvir e escrever tudo o que lhe chega à percepção, como importante para esclarecimento do seu objeto de estudo. Como obter consentimento informado livre e esclarecido de todos os sujeitos que estão no campo de pesquisa? Como adentrar a casa das pessoas, conhecer sua família, o modo como vivem as pessoas nesse grupo? E as instituições, como os serviços de saúde? Estas são apenas algumas das questões éticas levantadas e que os pesquisadores que enveredam por este campo de estudo precisam equacionar. Apesar das profundas transformações produzidas, o elemento principal que caracteriza ainda hoje a pesquisa etnográfica fundamenta-se na observação cuidadosa das práticas realizadas, em uma contínua tensão entre análise científica e experiência da vida quotidiana.

\section{Colaboradores}

Andrea Caprara foi responsável pela concepção do trabalho e desenvolvimento da introdução e primeira parte. Lucyla Paes Landim participou na concepção, coleta e interpretação da pesquisa apresentada na segunda parte.

\section{Referências}

ALENCAR, R. Viver com seqüelas das funções orais decorrentes do câncer de boca: histórias de vida. 2006. Dissertação (Mestrado) - Curso de Mestrado Acadêmico em Saúde Pública, Universidade Estadual do Ceará, Fortaleza. 2006.

ALMEIDA FILHO, N. Integração metodológica na pesquisa em saúde: nota crítica sobre a dicotomia quantitativo-qualitativo. In: GOLDENBERG, P.; MARSIGLIA, R.M.G.; GOMES, M.H.A. (Orgs.). O clássico e o novo: tendências, objetos e abordagens em ciências sociais e saúde. Rio de Janeiro: Fiocruz, 2003. p.143-56.

\section{ALMEIDA FILHO, N. et al. Etnografia da prática epidemiológica em dois estudos de} avaliação. Salvador: ISC/ UFBA, s.d.

ALVES, P.C. Repensando os estudos sobre representações e práticas em saúde e doença. In: RABELO, M.C.; ALVES, P.C. (Orgs.). Antropologia da saúde: traçando identidade e explorando fronteiras. Rio de Janeiro: Relume Dumará, 1998. p.107-21.

ANDRADE, G.R.B.; VAITSMAN, J. Apoio social e redes: conectando solidariedade e saúde. Ciênc. Saúde Colet., v.7, n.4, p.925-34, 2002.

APPADURAI, A. Modernity at large: cultural dimensions of globalization. Minneapolis: University of Minnesota Press, 1996. 
ATKINSON, S.J. Anthropology in research on the quality of health services. Cad. Saúde Pública, v.9, n.3, p.283-99, 1993.

BANYAI, I. Zoom. Rio de Janeiro: Brinque-Book, 2002.

BENINI, P.; NACLERIO, R. La ricerca qualitativa nelle scienze sociali. Disponível em: $<$ http://wwwesterni.unibg.it/siti_esterni/sde/matriciculturali/documenti_files/ RICERCA\% 20QUALITATIVA.htm > . Acesso em: 01 out. 2004.

BIBEAU, G. Le Québec transgénique: science, marché, humanité. Montréal: Boréal, 2004.

BONET, O. Saber e sentir: uma etnografia da aprendizagem da biomedicina. Rio de Janeiro: Fiocruz, 2004.

BOSI, E. Memória e sociedade: lembranças de velhos. 3.ed. São Paulo: Companhia das Letras, 1994.

BRINK, P.J.; EDGECOMBE, N. What is becoming of ethnography? Qual. Health Res., v.13, n.7, p.1028-30, 2003.

CAPRARA, A. Cultural interpretations of contagion. Trop. Med. Int. Health, v.3, n.12, p.996-1001, 1998.

CARDOSO DE OLIVEIRA, R. O trabalho do antropólogo. 2.ed. Brasília: Paralelo 15, 2000.

CERTEAU, M.; GIRAD, L.; MAYOL, P. A invenção do cotidiano: morar, cozinhar. 5.ed. Petrópolis: Vozes, 2003. v.2.

CLIFFORD, J. A experiência etnográfica: antropologia e literatura no século XX. Rio de Janeiro: UFRJ, 2002.

CLIFFORD, J.; MARCUS, G. Writing culture: the poetics and politics of ethnography. Berkeley: University of California Press, 1986.

DA SILVA, C.T. Sobre a interpretação antropológica: Sahlins, Obeysekere e a racionalidade havaiana. Rev. Antropol. USP, n.45, p.403-15, 2002.

DAMATTA, R. A casa e a rua: espaço, cidadania, mulher e morte no Brasil. 6.ed. Rio de Janeiro: Rocco, 2000.

DURHAM, E. R. A dinâmica da cultura. São Paulo: Cosac \& Naify, 2004.

A pesquisa antropológica com populações urbanas: problemas e perspectivas. In: CARDOSO, R. C. L. (Org.). A aventura antropológica: teoria e pesquisa. Rio de Janeiro: Paz e Terra, 1997. p.17-38.

. (Org.). Malinowski. São Paulo: Ática, 1986.

FABIETTI, U. Antropologia culturale. L'esperienza e l'interpretazione. Roma: Laterza, 1999.

FABIETTI, U.; REMOTTI, F. Dizionario di antropologia, voce etnografia. Bologna: Zanichelli, 1997.

GEERTZ, C. Nova luz sobre a antropologia. Rio de Janeiro: Jorge Zahar, 2000. From the native's point of view: on the nature of anthropological understanding. In: . Local knowledge: further essays in interpretive anthropology. London: Harper Collins United Kingdom, 1993. p.55-70.

A interpretação das culturas. Rio de Janeiro: LTC Editora, 1989. 
GOMES, R. et al. Avaliação da assistência ambulatorial a portadores de HIV/AIDS no Rio de Janeiro, segundo a visão de seus usuários. Cad. Saúde Pública, n.15, p.789-97, 1999.

HAMMERSLEY, M.; ATKINSON, P. Etnografía: métodos de investigación. Barcelona: Paidós, 1994.

INSTITUTO BRASILEIRO DE GEOGRAFIA E ESTATÍSTICA - IBGE. Perfil dos idosos responsáveis pelos domicílios no Brasil. Rio de Janeiro: IBGE, 2000.

IRIART, J.A.; ANDRADE, T.M. Body-building, steroid use, and risk perception among young body-builders from a low-income neighborhood in the city of Salvador, Bahia State, Brazil. Cad. Saúde Pública, v.18, n.5, p.1379-87, 2002.

JONES, J.; HUNTER, D. Qualitative research: consensus methods for medical and health services research. Br. Med. J, n.311, p.376-80, 1995.

KILLINGER, C.L. et al. Etnografia do saneamento, limpeza e saúde: um estudo de caso nas unidades domésticas. Ciênc. Saúde Colet., v.5, supl., p.83, 2000.

LAPLANTINE, F. Aprender antropologia. São Paulo: Brasiliense, 2001.

LATOUR, B.; WOOLGAR, S. A vida de laboratório: a produção de fatos científicos. Rio de Janeiro: Relume Dumará, 1997.

LÉVI-STRAUSS, C. O olhar distanciado. Lisboa: Edições 70, 1986.

LOCK, M. Contesting the natural in Japan: moral dilemmas and technologies of dying. Cult. Med. Psychiatry, n.19, p.1-38, 1995.

MALINOWSKI, B. Introdução: o assunto, o método e o objetivo desta investigação. In: DURHAM, E.R. (Org.). Malinowski. São Paulo: Ática, 1986. p.24-48.

MEYER, J. Qualitative research in health care. Using qualitative methods in health related action research. Br. Med. J, n.320, p.178-81, 2000.

MENEZES, R.A. Etnografia do ensino médico em um CTI. Interface - Comunic., Saúde, Educ., v.5, n.9, p.117-30, 2001.

MINAYO, M.C.S. O desafio do conhecimento: pesquisa qualitativa em saúde. São Paulo: Hucitec, 2000.

MINAYO, M.C.S.; MINAYO-GÓMEZ, C. Difíceis e possíveis relações entre métodos quantitativos e qualitativos nos estudos de problemas de saúde. In: GOLDENBERG, P.; MARSIGLIA, R.M.G.; GOMES, A.M.H. (Orgs.). O clássico e o novo: tendências, objetos e abordagens em ciências sociais e saúde. Rio de Janeiro: Fiocruz, 2003. p.117-42.

NATIONS, M.K.; GOMES, A.M.A. Cuidado, "cavalo batizado" e crítica da conduta profissional pelo paciente-cidadão hospitalizado no nordeste brasileiro. Cad. Saúde Pública, v.23, n.9, p.2103-12, 2007.

NATIONS, M.K.; NUTO, A.S.S. Tooth worms, poverty tattoos and dental care conflicts on Northeast Brazil. Soc. Sci. Méd., n.54, p.229-44, 2002.

NUNES, M. Da clínica à cultura: uma etnografia da relação terapêutica no contexto "PSI" na Bahia, Brasil. 1993. Dissertação (Mestrado) - Faculdade de Medicina, Departamento de Medicina Preventiva, Universidade Federal da Bahia, Salvador. 1993.

OBEYESEKERE, G. The apotheosis of captain cook: european mythmaking in the pacific. Princeton: Princeton University Press, 1997. 
PAES LANDIM, L. O entardecer no farol: um estudo etnográfico sobre a percepção da saúde entre pessoas idosas. 2004. Dissertação (Mestrado) - Curso de Mestrado Acadêmico em Saúde Pública, Universidade Estadual do Ceará, Fortaleza. 2004.

PAIM, J.S.; ALMEIDA FILHO, N. Saúde coletiva: uma "nova saúde pública" ou campo aberto a novos paradigmas? Rev. Saúde Pública, v.32, n.4, p.299-316, 1998.

PATTON, M. Q. Qualitative evaluation and research methods. Newbury Park: SAGE Publications, 1987.

PIZZA, G. Antropologia medica: saperi, pratiche e politiche del corpo. Roma: Carocci, 2005.

POPE, C.; MAYS, N. (Eds.). Qualitative research in health care. London: BMJ Books, 2000.

RABINOW, P. Antropologia da razão. Rio de Janeiro: Relume Dumará, 1999. Press, 1996

Making PCR: a story of biotechnology. Chicago: The University of Chicago

REGO, R.C.; BARRETO, M.L.; KILLINGER, C.L. What is garbage, anyway? The opinions of women from an outlying neighborhood in a large Brazilian city. Cad. Saúde Pública, v.18, n.6, p.1583-91, 2002.

RODRIGUES, N.; CARDOSO, C.A. Idéia de sofrimento e representação cultural da doença na construção da pessoa. In: DUARTE, L.F.D. (Org.) Doença, sofrimento, perturbação: perspectivas etnográficas. Rio de Janeiro: Fiocruz, 1998. p.137-49.

ROSALDO, R. Culture \& truth: the remaking of social analysis. Boston: Beacon Press, 1993.

SOUZA, I.M.A. Um retrato de Rose: considerações sobre processos interpretativos e elaboração de história de vida. In: DUARTE, L.F.D.; LEAL, O.F. (Orgs.). Doença, sofrimento, perturbação: perspectivas etnográficas. Rio de Janeiro: Fiocruz, 1998. p.151-68.

TRAD, L.A.B. et al. Estudo etnográfico da satisfação do usuário do Programa de Saúde da Família (PSF) na Bahia. Ciênc. Saúde Colet., v.7, n.3, p.581-9, 2001.

VAN MANEN, M. (Org.). Writing in the dark: phenomenological studies in interpretive inquiry. Ontario: The The Althouse Press, 2002.

Researching lived experience: human science for an action sensitive pedagogy. Ontario: The University of Western Ontario, 1990.

VÍCTORA, C.G; KNAUTH, D.; HASSEN, M.N. Pesquisa qualitativa em saúde. Porto Alegre: Tomo Editorial, 2001.

WIKLUND, L.; LINDHOLM, L.; LINDSTRÖM, U.A. Hermeneutics and narration: a way to deal with qualitative data. Nurs. Inqu., v.9, n.2, p.114-25, 2002.

ZALUAR, A. Exclusão e políticas públicas: dilemas teóricos e alternativas políticas. Rev. Bras. Cienc. Soc., v.12, n.25, p.29-47, 1997. 
CAPRARA, A.; LANDIM, L.P. Etnografia: uso, potencialidades y límites en la pesquisa en salud. Interface - Comunic., Saúde, Educ., v.12, n.25, p.363-76, abr./jun. 2008.

El método etnográfico viene siendo crecidamente utilizado para estudiar una variedad de temas en el área de la salud como: el funcionamento y evaluación del sistema sanitario; la investigación epidemiológica; la pesquisa científica de laboratorio; la pesquisa biotecnológica; la pesquisa genética, entre otros. Esto nos lleva a formular algunas preguntas metodológicas a partir de la lectura de estos trabajos: ¿cómo se ha ido transformado la pesquisa etnográfica en los ultimos decenios? ¿Qué elementos caracterizan la pesquisa etnográfica aplicada en salud? Buscando reflexionar sobre estas cuestiones desarrollamos el artículo mediante dos sucesivos desdoblamientos: 1 el desarrollo del método etnográfico de pesquisa y su utilización en la pesquisa en salud; 2 los aspectos metodológicos de una pesquisa etnográfica realizada con ancianos en la ciudad de Fortaleza, estado de Ceará, Brasil, enfocando el interés sobre la observación participante.

Palabras clave: Etnografía. Investigación cualitativa. Observación. Salud pública.

Recebido em 28/03/07. Aprovado em 14/12/07. 